\title{
Anafilaxia a alfa-gal: um relato de caso paraibano
}

\author{
Alpha-gal anaphylaxis: a case report from Paraíba, Brazil \\ Renata de Cerqueira Paes Correa Lima1, Constantino Giovanni Braga Cartaxo', \\ Wanne Sabrini Silva de-Brito ${ }^{1}$
}

\section{RESUMO}

O presente relato apresenta um caso de anafilaxia tardia ao carboidrato alfa-gal em um adolescente da cidade de Belém, na Paraíba, Brasil. O paciente desenvolveu reação tardia à ingesta de carne e vísceras de animais. Ele mora em fazenda e tem contato próximo com animais potencialmente contaminados por carrapatos. Essa causa de reação alérgica é nova, e estudos começaram a atribuí-la a casos antes ditos idiopáticos. A anafilaxia é uma reação potencialmente fatal, que deve ser prontamente diagnosticada e tratada. Sendo assim, a descoberta de seu fator desencadeante é um dos principais itens que direcionam o tratamento. No Brasil, nenhum caso de anafilaxia por alfa-gal foi antes descrito na literatura local.

Descritores: Anafilaxia, vísceras, carne vermelha, alergia a alfa-gal.

\section{Introdução}

A anafilaxia é uma doença prevalente e grave, cuja fisiopatologia envolve reação de hipersensibilidade. Acomete tipicamente dois ou mais órgãos e sistemas, com evolução rápida, podendo ocorrer choque e/ou falência respiratória como desfechos. Estudos demonstram que o quadro tem sido subdiagnosticado em cerca de $58 \%$ dos casos de reações alérgicas e anafiláticas em crianças atendidas na urgência ${ }^{1}$.

A frequência exata dos quadros de anafilaxia na população geral é desconhecida, pelo baixo reconhecimento dos sintomas, tanto pelos pacientes quanto pelos profissionais da área de saúde ${ }^{2}$. Estima-se que $1 \mathrm{em}$ cada 200 atendimentos nos serviços de

\section{ABSTRACT}

This report presents a case of late anaphylaxis to alpha-gal carbohydrate in a teenager living in the city of Belém, Paraíba, Brazil. The patient developed a late reaction to eating meat and offal of animals; he lives on a farm and has close contact with animals potentially contaminated by ticks. This cause of allergic reaction is new, and studies have started to attribute it to cases previously said to be idiopathic. Anaphylaxis is a potentially fatal reaction that must be promptly diagnosed and treated. Thus, the discovery of its triggering factor is one of the main items that guide treatment. In Brazil, no case of alpha-gal anaphylaxis had been described in the local literature.

Keywords: Anaphylaxis, viscera, red meat, alpha-gal allergy.

emergência seja por reações de hipersensibilidade, e que existam 50-2.000 episódios de anafilaxia para cada 100.000 pessoas no curso da vida, ou seja, 0,05 a $2 \%$ da população geral ${ }^{3}$. Como fatores de risco são descritos a idade (predomina em adolescentes e adultos jovens), comorbidades como asma e outros quadros respiratórios, dermatite atópica, doenças cardíacas, distúrbios psiquiátricos e uso de medicações, como betabloqueador e inibidor da enzima conversora de angiotensina ${ }^{4}$.

O início agudo, em minutos ou horas, com acometimento de pele e/ou mucosas, sistema respiratório, cardiovascular e gastrointestinal, de forma isolada ou

1. Universidade Federal da Paraiba, Departamento de Pediatria e Genética - Centro de Ciências Médicas - João Pessoa, PB, Brasil. 
associada, após exposição a um provável alérgeno, com ou sem redução rápida da pressão arterial, são critérios para o diagnóstico do quadro ${ }^{4}$. O tratamento recomendado na sala de emergência é a adrenalina via intramuscular (IM) na dose de $0,01 \mathrm{~mL} / \mathrm{kg}$ da solução 1:1000 (dose máxima de 0,3 $\mathrm{mL} /$ dose em menores de 12 anos e $0,5 \mathrm{~mL} /$ dose em maiores de 12 anos). Como outras drogas de segunda linha podemos citar o glucagon, anti-histamínicos de primeira/ segunda geração, corticoides e broncodilatadores inalatórios².

Publicações recentes descrevem um tipo de anafilaxia, geralmente grave, em pacientes que possuem anticorpo IgE contra o carboidrato galactose-alfa-1,3galactose (alfa-gal); este é expresso em proteínas de mamíferos não primatas e no cetuximab, anticorpo usado para tratamento de câncer colorretal metastático e de câncer de cabeça e pescoço recorrente. Acredita-se que esses pacientes que apresentaram reações graves a essa substância foram previamente sensibilizados pelo carboidrato presente na saliva de carrapatos da espécie Amblyomma americanum, endêmicos nas áreas dos Estados Unidos da América, onde os casos ocorreram inicialmente ${ }^{5}$.

\section{Relato de caso}

G.A.N., sexo masculino, 17 anos, natural e procedente de Belém, $\mathrm{PB}$, apresentou um episódio de dispneia, lesões urticariformes por todo o corpo e edema facial iniciados durante o sono, duas horas após ingesta de churrasco de rim de porco acompanhado de bebida alcoólica destilada. Em atendimento no Pronto-Socorro (PS) foi medicado com anti-histamínico, corticosteroide, adrenalina (intramuscular) e oxigenioterapia. Recebeu alta após 10 horas de observação. Cerca de um ano e meio após este evento, apresentou outro episódio anafilático seis horas após comer vísceras de carneiro cozidas. Chama a atenção o fato de que o paciente comeu o mesmo prato um mês antes e não apresentou nenhum sintoma.

Como antecedentes, o paciente referiu rinite alérgica desde a infância. Negou asma ou dermatite atópica. Reside em zona rural e tem contato com animais (vacas, cavalos e cachorros) desde criança. Não relatou picadas de carrapato, mas admitiu a alta probabilidade de exposição pelo seu contato próximo com os animais.

$\mathrm{Na}$ investigação realizada, apresentou IgE total $=1349 \mathrm{KU} / \mathrm{L}$, IgE para ácaros $=16,2 \mathrm{KU} / \mathrm{L}$, IgE para epitélio de gato $=34,1 \mathrm{KU} / \mathrm{L}$, IgE para epitélio de cão $=3,97 \mathrm{KU} / \mathrm{L}$, IgE para carne de porco $=$ inferior a $0,1 \mathrm{KU} / \mathrm{L}$, IgE para carne de vaca = inferior a $0,1 \mathrm{KU} / \mathrm{L}$, IgE para alfa-gal $=64,3 \mathrm{KU} / \mathrm{L}$ e IgE para fungos $=1,56 \mathrm{KU} / \mathrm{L}$.

Atualmente, o paciente não ingere carne de porco. Porém, consome carne bovina normalmente. Apresenta quadro de rinite alérgica controlada com uso de mometasona (corticoide nasal) e desloratadina (anti-histamínico de segunda geração). Foi orientado a evitar vísceras de mamíferos no geral, além de manter controle ambiental para ácaros e epitélios de animais. Paciente mantém contato com bois e cavalos, porque relata que os animais são seu hobby.

\section{Discussão}

A primeira descrição de urticária ou anafilaxia horas após a ingesta de carne de mamíferos associada ao antecedente de picada de carrapatos foi feita, inicialmente, em 1989, na Sociedade de Alergia da Geórgia ${ }^{6}$. Em 2007, essa correlação foi novamente levantada pela Profa. Sheryl van Nunen, na Austrália. Posteriormente, estudos do Prof. Thomas Platts-Mills, realizados na Virgínia, Estados Unidos da América (EUA), confirmaram esta associação e a correlacionaram com a existência de um oligossacarídeo chamado galactose-alfa-1,3-galactose (alfa-gal). As pesquisas de Platts-Mills foram feitas, inicialmente, por meio da observação de ocorrência de reação de hipersensibilidade imediata (pico em 20 minutos) após uso de cetuximab em pacientes com câncer de cólon metastático. As reações ocorriam apenas em uma região específica dos EUA, na qual, posteriormente, iniciaram-se quadros de anafilaxia tardia ao consumo de carne de mamíferos não primatas. Por meio de estudos de carrapatos do gênero Amblyomma, abundantes na região, ocorreu a comprovação de que os seres humanos desenvolviam anticorpos IgE específicos para alfa-gal, através da picada de carrapatos que continham o carboidrato na sua saliva. Consequentemente, as pessoas eram sensibilizadas, apresentando, posteriormente, a reação de hipersensibilidade quando expostas à medicação ou às carnes ${ }^{6-9}$.

O antígeno alfa-gal está presente em eritrócitos, carne vermelha e tecidos de mamíferos não primatas, principalmente vacas, porcos, carneiros, coelhos, cavalos e cangurus. Os anticorpos anti alfa-gal estão presentes em todos os humanos imunocompetentes e representam a maior barreira ao transplante entre 
primatas e outros mamíferos. Esses anticorpos representam $1 \%$ das nossas imunoglobulinas circulantes ${ }^{10}$. A ausência do oligossacarídeo no homem decorre da inatividade do gene codificador do alfa-gal em humanos e primatas superiores, impossibilitando, então, a síntese desse epítopo. Tal inativação parece decorrer de mecanismos de proteção dos ancestrais humanos e mamíferos superiores contra organismos patogênicos possuidores do carboidrato alfa gal, como vírus envelopados, protozoários e bactérias ${ }^{11}$.

A fisiopatologia exata envolvida na resposta IgE específica para alfa-gal ainda não está completamente elucidada, de acordo com os estudos sobre o assunto. São descritos envolvimento de resposta típica IgG2 e resposta atípica Th2, conduzindo à produção de IgG1 e IgE, além do IgG2. Acreditase, também, que possam existir cofatores que influenciam no desencadeamento das crises, como uso concomitante de álcool, exercício físico, uso de analgésicos não hormonais, infecções e menstruação; isso ajuda a explicar o porquê de pessoas com IgE aumentada para alfa-gal não apresentarem alergia à carne vermelha em todas as ocasiões de exposição ${ }^{12}$. O paciente em questão fez uso de bebida alcoólica destilada acompanhando o churrasco de rim de porco.

Pacientes com alergia a alfa-gal devido à ingesta de carne vermelha têm resposta imune diferente daqueles com reação após uso de cetuximab. Esta envolve a ativação de basófilos de início rápido e pico em 20 minutos após início de uso da medicação, enquanto aqueles têm resposta de início tardio, em três a seis horas após ingesta de carne vermelha, vísceras, leite ou derivados. A resposta tardia é provavelmente decorrente do tempo necessário para entrada na circulação dos oligossacarídeos absorvidos no trato digestivo ${ }^{13}$. O paciente evoluiu com sintomas duas horas após o consumo no primeiro episódio, e seis horas após no segundo episódio.

A apresentação clínica decorrente da sensibilização ao oligossacarídeo pode ocorrer como urticária generalizada, angioedema, sintomas gastrointestinais e/ou anafilaxia de início tardio, três a seis horas após o consumo. Vale ressaltar que o fato de ser tardio pode atrasar o diagnóstico etiológico, já que nem os pacientes nem os médicos conseguem estabelecer correlação entre a ingesta da carne e a reação ${ }^{14}$.

O consumo de vísceras, principalmente rins de porcos e carnes gordurosas, está associado a maior probabilidade de desenvolver a reação alérgica mais grave, decorrente do maior conteúdo do carboidrato alfa-gal encontrado nesses órgãos em comparação com a carne proveniente dos músculos dos animais ${ }^{15}$. O nosso paciente tolera a carne bovina, tendo apresentado reações com vísceras de porco e carneiro.

O epítopo alfa-gal presente na saliva de espécies de carrapatos é inoculado após a picada em humanos, juntamente com prostaglandinas, lipocalinas, fosfolipases e adenosina, também presentes na saliva do carrapato. Juntos, desencadeiam a resposta imunológica que atua no epitélio e em células imunes subepiteliais, determinando sensibilização com indução à síntese de $\mathrm{IgE}$ específica em reação envolvendo citocinas da resposta imune T helper tipo 2. Tal sensibilização parece ocorrer em áreas não específicas (fora de centros germinativos), como na mucosa nasal ${ }^{13}$.

A picada do carrapato é a provável responsável pela sensibilização prévia das pessoas que apresentam a anafilaxia tardia à carne vermelha. Existem estudos prospectivos que mostram aumento maior que 20 vezes nos níveis de IgE para alfa-gal após picadas de carrapatos. O gênero Amblyomma é o mais numeroso no Brasil e o de maior importância médica, porque a ele pertencem as principais espécies que parasitam os humanos no país ${ }^{16}$. O nosso paciente não relata a ocorrência de picadas de carrapatos, mas mora em zona rural e tem contato frequente com animais. Outros casos são descritos em pacientes sem histórico de picadas de carrapatos, porém que trabalham em ambiente rural ${ }^{17}$.

Testes cutâneos e intradérmicos não são apropriados para o diagnóstico, sendo possível a ocorrência de testes falso-negativos, mesmo na vigência da reação ao carboidrato alfa-gal. O mais apropriado é a dosagem sérica da IgE específica contra alfa-gal, que seria positiva em valores elevados para os pacientes nos quais o carboidrato foi, de fato, a causa da alergia ${ }^{18}$. Níveis séricos de IgE para alfa-gal $>5,5 \mathrm{KU} / \mathrm{L}$ predizem uma probabilidade de $95 \%$ do paciente apresentar alergia a carnes vermelhas, e quanto maior for o valor de IgE para o carboidrato, mais grave será a sintomatologia do doente ${ }^{19}$. A maioria dos doentes com alergia à carne vermelha por hipersensibilidade a alfa-gal apresenta níveis de $\lg E$ elevados para carne de vaca, porco, carneiro, epitélio de gato, pelo de cão e leite de vaca. O paciente do caso apresenta níveis elevados de IgE para epitélio de gato. Isso ocorre, provavelmente, devido a resíduos de alfa-gal presentes na IgA do gato ${ }^{20}$.

O manejo clínico específico da hipersensibilidade alfa-gal IgE mediada é suspender o consumo de 
carne vermelha e evitar a exposição às picadas de carrapato, medidas que trazem consigo a remissão completa dos sintomas e redução dos níveis de sensibilização da lgE específica. Pacientes que não são expostos às picadas de carrapatos por um a dois anos apresentam diminuição significativa nos níveis de IgE específica, tornando-se tolerantes até mesmo ao consumo posterior da carne vermelha ${ }^{21}$. Como exposto no relato, foi orientado que o adolescente suspendesse o consumo das vísceras que desencadearam as crises, porém, o contato com animais foi mantido por desejo do paciente.

É válido ressaltar que no Brasil existe na literatura apenas um relato de urticária crônica associada à alergia a alfa-gal, que ocorreu em um homem adulto do estado de Rondônia²2.

\section{Referências}

1. Huang F, Chawla K, Järvinen KM, Nowak-Weegrzyn A. Anaphylaxis in a New York City pediatric emergency department: Triggers, treatments, and outcomes. Bone. 2012;23(1):1-7.

2. Simons FER, Ardusso LRF, Bilò MB, El-Gamal YM, Ledford DK, Ring J, et al. World allergy organization guidelines for the assessment and management of anaphylaxis. Japanese J Allergol. 2014;62(11):1464-500.

3. Simons FER. Anaphylaxis. J Allergy Clin Immunol. J Allergy Clin Immunol. 2010;125(Suppl 2):S161-8.

4. Silva MTN. Alergia e Imunologia . In: Burns DAR, Campos Júnior D, Silva LR, Borges WG, Blank D; Sociedade Brasileira de Pediatria. Tratado de Pediatria. São Paulo: Manole; 2017. p. 445-6.

5. Domingues-Ferreira M, Paia Neto L, Ribeiro RG. Alergia a alfa-gal: uma revisão sistemática. Braz J Allergy Immunol. 2015;3(6):241-50.

6. Steinke JW, Platts-Mills TAE, Commins SP. The alpha-gal story: Lessons learned from connecting the dots. J Allergy Clin Immunol [Internet]. 2015;135(3):589-96.

7. Platts-Mills TAE, Schuyler AJ, Hoyt AEW, Commins SP. Delayed anaphylaxis involving IgE to galactose-alpha-1,3-galactose. Curr Allergy Asthma Rep. 2015;15:12.

8. Commins SP, Jerath MR, Cox K, Erickson LD, Platts-Mills T. Delayed anaphylaxis to alpha-gal, an oligosaccharide in mammalian meat. Allergol Int [Internet]. 2016;65(1):16-20.

9. Platts-Mills TA, Schuyler AJ, Tripathi A, Commins SP. Anaphylaxis to the carbohydrate side chain alpha-gal. Immunol Allergy Clin North Am. 2015 May;35(2):247-60.
10. Galili U, Rachmilewitz EA, Peleg A, Flechner I. A unique natural human IgG antibody with anti-alpha-galactosyl specificity. J Exp Med. 1984;160:1519-31.

11. van Nunen S. Tick-induced allergies: Mammalian meat allergy, tick anaphylaxis and their significance. Asia Pac Allergy. 2015;5(1):3-16.

12. Fischer J, Biedermann T. Delayed immediate-type hypersensitivity to red meat and innards: current insights into a novel disease entity. J Dtsch Dermatol Ges. 2016 Jan;14(1):38-44.

13. Steinke JW, Platts-Mills TAE, Commins SP. The alpha-gal story: Lessons learned from connecting the dots. J Allergy Clin Immunol [Internet]. 2015;135(3):589-96.

14. Fischer J, Yazdi AS, Biedermann T. Clinical spectrum of $\alpha$-Gal syndrome: from immediate-type to delayed immediate-type reactions to mammalian innards and meat. Allergo J Int. 2016;25:55-62.

15. Fischer J, Hebsaker J, Caponetto P, Platts-Mills TA, Biedermann T. Galactose-alpha-1,3-galactose sensitization is a prerequisite for pork-kidney allergy and cofactor-related mammalian meat anaphylaxis [Letter].J Allergy Clin Immunol.2014 Sep;134(3):755-9. e1. doi: 10.1016/j.jaci.2014.05.051.

16. Rispens T, Derksen NI, Commins SP, Platts-Mills TA, Aalberse $\mathrm{RC}$. IgE production to $\alpha$-gal is accompanied by elevated levels of specific IgG1 antibodies and low amounts of IgE to blood group B. PLoS One. 2013;8(2):e55566.

17. Pita J, Ciobanu A, Loureiro C, Bom AT. Alergia a galactose- $\alpha-1,3-$ galactose. Rev Port Imunoalergologia. 2018;26(1):11-19.

18. São Paulo, Brasil. Secretaria de Estado da Saúde.Superintendência de Controle de Endemias - SUCEN. Manual de vigilância acarológica. Camargo-Neves VLF (coord.). São Paulo: SES; 2004. p. 62.

19. Mabelane T, Basera W, Botha M, Thomas HF, Ramjith J, Levin ME. Predictive values of alpha-gal IgE levels and alpha-gal lgE:Total IgE ratio and oral food challenge-proven meat allergy in a population with a high prevalence of reported red meat allergy. Pediatr Allergy Immunol. 2018;29(8):841-9.

20. Stewart $P$, McMullan K, Le Blanc S. Delayed red meat allergy: clinical ramifications of galactose- $\alpha-1,3$-galactose sensitization. Ann Allergy Asthma Immunol. 2015;115:260-4.

21. Ferreira MD, Piaia Neto L, Ribeiro RG. Alergia a alfa-gal: uma revisão sistemática. Braz J Allergy Immunol. 2015;3(6):241-50.

22. Cocco RR, Ensina LF, Aranda CS, Solé D. Galactose- $\alpha-1,3-$ galactose (alpha gal) allergy without anaphylaxis: a case report in Brazil. Clinical and Translational Allergy. 2017;7(Suppl 1):PP159.

Não foram declarados conflitos de interesse associados à publicação deste artigo.

Correspondência:

Renata de Cerqueira Paes Correa Lima

E-mail: paes.renata@ig.com.br 